\title{
Development of an experimental micro smart grid with renewable sources and energy storage through final Electronics Engineering projects
}

Sergio Junco

LAC, Laboratorio de Automatización y Control. FCEIA, Facultad de Ciencias

Exactas, Ingeniería y Agrimensura.

UNR, Universidad Nacional de Rosario Rosario, Argentina

sjunco@fceia.unr.edu.ar
Daniel Alba

LAC, Laboratorio de Automatización y Control. FCEIA, Facultad de Ciencias

Exactas, Ingeniería y Agrimensura.

UNR, Universidad Nacional de Rosario

Rosario, Argentina

alba@fceia.unr.edu.ar

Javier Cabello

LAC, Laboratorio de Automatización y

Control. FCEIA, Facultad de Ciencias

Exactas, Ingeniería y Agrimensura.

UNR, Universidad Nacional de Rosario

Rosario, Argentina

jcabello@fceia.unr.edu.ar
Joaquín Ezpeleta

LAC, Laboratorio de Automatización y Control. FCEIA, Facultad de Ciencias

Exactas, Ingeniería y Agrimensura.

UNR, Universidad Nacional de Rosario

Rosario, Argentina

ezpeleta@fceia.unr.edu.ar

\begin{abstract}
This paper addresses the involvement of Electronic Engineering students in the development of an electric micro smart grid equipped with renewable energy sources and storage components through the execution of their final engineering projects as part of the regular curriculum. First, the pre-defined overall target smart grid is introduced, followed by its current state of development. Then, the context of the students' participation is presented, followed by the description of their input as modular contributions to a sequentially conceived process leading to the final target system. The conclusions stress the learning-by-doing feature of the students' involvement, that not only helps to consolidate the theoretical, methodological and practical skills previously acquired but also puts the students in contact with new technologies and engineering problems and systems, and provides abilities regarding teamwork and participation in relatively long-term project.
\end{abstract}

Keywords-Micro smart grids, electronic power converters, embedded control systems, CAN communication, learning-by-doing. 